\title{
Life Planning / Strategic Planning / Financial Planning
}

\author{
E. J. Roy Knaus, (Email: knaus@wpunj.edu) William Paterson University
}

\begin{abstract}
This Paper examines a technique for doing 'Life Planning'. The technique is one that has been tested by the author in a number of sections of a business school's capstone course. The study is empirical in nature, applying concepts found, mainly, in strategic planning but, also in psychology, career planning and financial planning.
\end{abstract}

If you don't know where you are going, any road will take you there.

"Alice in Wonderland", Lewis Carroll

\section{INTRODUCTION}

he main focus of this paper is on the areas of life, strategic and financial planning. The proposed method of life planning is derived from strategic planning, while the financial planning's use of life planning is discussed as an illustration of attempts to bring this subject into other applied areas.

Life Planning is the process of developing and examining major lifetime decisions. It is the study of: who I am, what I am, what I need and what I expect (Hollis \& Hollis, 1979). The process is a formal one of developing and evaluating a plan for ones life.

The term 'Life Planning' has been in multi-disciplinary literature for many years and in a number of disciplines. However, the term tends most often to appear as an add-on to a more specialized area. For example, in areas like career planning and financial planning, 'Life planning' is added to the model under consideration to bring in additional factors than are available in the basic model of career and financial planning. There appears not to be a specific 'Life Planning' model. The research direction of this paper is to develop a model specifically designed to 'Life Planning'.

\section{FINANCIAL PLANNING}

Life planning has been heavily discussed in the area of financial planning in the last two years (Perry 2003). A number of factors seem to have stimulated this activity. The horror of September 11 has prompted us to think more about our own survivorship issues and to re-evaluate our daily lives (Wasik, 2003). The oncoming wave of babyboomers and their issues of retirement and security, along with a more rapidly changing global picture are resulting in greater introspection and self-analysis. One can see the impact of this trend in the TV advertisements of the major firms that offer financial advise. No longer do you see explanations of financial products or charts. The typical view is that of a mature couple walking into the sunset on a beautiful tropical beach. The appeal is to peoples needs and desires and not the means of achieving the.

There are several leaders who have been promoting the use of life planning as a part of financial planning. They have not only used life planning in their own financial planning but have begun consulting organizations that offer several day seminars for financial planner to learn how to bring life planning into their practices. Mitch Anthony's Institute for Financial Life Planning refer to their approach as asking the right questions, and therefore being able to engage the client in meaningful conversations about important life events, situations and goals (Business Wire, 2004). George D. Kinder, founded the Kinder institute in the mid nineties and is considered to be the founder of life planning in the financial planning discipline (Miller, 2004). Kinder, also the author of bestseller, 'The Seven Stages of Money Maturity', characterizes his approach as the human side of financial planning. To be more precise, it 
is the process of first identifying what our clients' most profoundly desire and then having the professional, as well as the personal skills to help them achieve their dreams in the shortest time and most efficient means possible (Miller, 2004). Peg Eddy gave a groundbreaking presentation in the early nineties in which she characterized life planning as trying to understand peoples deeply felt values about money, goals and dreams before figuring out how to finance them (Perry, 2003)

The philosophy of these pioneers is divided into two approaches, one of the attracting effects of positive emotions, versus the repulsing effect of negative emotions (Southall, 2004). There is agreement among most authors in the life planning area that the major institutions promise to make life better for you without a mechanism of determining what you believe is better.

The approach of life planning in financial planning is to determine the hidden goals and attitudes of the client through open-ended questions. This approach is added on the normal financial planning process. The questions used by Kinder are the following:

1. If you had all the money that you needed for now and the rest of your life, how would you live your life? What would you do? What would you do differently?

2. You go to the doctor, feeling perfectly health, and he tells you that you have a rare illness. The good news is that you will never feel sick. The bad news is that sometime five to ten years from now; you will die suddenly, without notice. Knowing that, how would you change your live now? What would your life look like?

3. This time at the doctor's, although you feel perfectly healthy, she tells you that you have a rare ailment, and that you only have 24 hours left to live. As you let the emotional impact settle in, consider these questions: What did you not get to do? Who did you not get to be? What did you miss?

The approach is a major step forward, and very functional in the financial planning process. However, it falls short of preparing a life plan in a number of regards. It allows the client to fanaticize. Of itself, this is a good starting point, but without a rigorous consideration of the resources and limitations required. I may want to be a ballet dancer, but if I have two left feet, no amount of financial resources or financial planning is going to help. Secondly, the implementation is only relative to finances, which is the purpose of the exercise from the financial planners view, but not from life planning. Some desired outcomes may have no financial requirements and are lost in the process. Thus, the model appears to be lacking in what its name of life planning implies. The model that will be pursued from here on will be a modification of the strategic planning model applied to an individual.

Unfortunately, while few people would choose a random walk, as a technique of determining their life path, most people follow this route rather than a more structured approach.

\section{STRATEGIC PLANNING}

The basis of this discussion is the model developed and used by the author in the capstone course of a business curriculum. The exercise was developed as method of testing and reinforcing the students understanding of the strategic planning model. It was found to be a powerful motivator for the students, giving them an understanding of the life decisions, which they had to make and how they are interrelated.

\section{The Strategic Planning Model}

The Strategic Planning Model consists of four basic processes:

1. Environmental Scanning

2. Strategy Formulation

3. Strategy Implementation

4. Evaluation and Control

This type model is known as the four-step model. It is the basis of the strategic planning model, but is also a general model used in many different areas of business, where action decisions are required. It basically says: What is 
the context of the decision? What are the strategic alternatives? What are the measurable steps to carrying out the strategies? And, Measure the results and readjust the model.

The more expanded form of the model is shown below in the sequence of steps that it is done:

\section{Environmental Scanning:}

1. External Factors

2. Internal Factors

Environmental Scanning is the determination and evaluation of information from the external and internal environments that will impact the companies' performance. These are essentially the strategic factors that will determine the future of the company. This is also known as the SWOT analysis. The external factors represent the opportunities and the threats. The internal factors represent the strengths and weaknesses. This is essentially the context of the decision; the collection of factors that determines what the company can and cannot do.

Strategy Formulation:

1. Mission

2. Objectives

3. Strategies

4. Policies

Strategy formulation is the development of the 'how' the corporation will effectively manage in light of environmental opportunities and threats, in light of corporate strengths and weaknesses. It includes defining the corporate mission, specifying achievable objectives, developing strategies and setting policy guidelines.

Strategy Implementation:

1. Programs

2. Budgets

3. Procedures

Strategy implementation is the process by which strategies and policies are put into action. This involves the day-to-day decisions on resource allocation.

\section{Evaluation and Control}

Evaluation and Control is the process in which corporate activities and performance results are monitored so that actual performance can be compared with desired performance. There is a feedback lope from this to the other activities of the model to compare results to expectation.

The model is presented as a step-wise model, while in practice it is more of an iterative model.

The Strategic Planning model is, in reality, a very simple model. It states: What is the context of the decisions - What basic strategy will we use to accomplish our mission. - How do we implement the strategy, - And, How do we monitor the results. While the basic concept of the model is quite simple, one semester of the capstone course is devoted to studying the model and all the theories, sub-models and concept that go with each aspect of the model. 


\section{LIFE PLANNING}

The intensity of study and detailed nature of the study of the strategic planning model created a problem in itself. Students never develop an appreciation of the flexibility of the model and its ability to handle complex and unstructured problems. Worse, its use can become a rote exercise for many students. To offset this problem and reinforce an understanding of the broad potential use of the model, students were assigned the task of using the model as a way of planning their life. While this appeared a little unorthodox in the beginning, it did make a great deal of sense. Whether you are planning the life of a corporation or an individual, the classes of considerations are the same. Doing such an exercise as this would indeed demonstrate an understanding of the model and its ability to handle complex and unstructured problems.

Needless to say, the assignment of a project, such as doing a strategic plan of your life, is normally met with a great deal of wailing and gnashing of teeth. Indeed, the instructor (author) also, had a certain degree of concern on the due ability of the assignment.

What follows, is the model that evolved and definitions.

\section{Area Of Analysis}

The first choice that must be made is that of how broad an area is to be chosen for the analysis. It can be as narrow as one aspect of a person's life such as: career. It can cover several areas that interact such as: career - health - leisure. Or it can cover all-important aspects of ones life. The scope of the study is left to the student since only they can define what is of most importance to them.

\section{Environmental Scanning}

\section{External Environment}

The factors here would relate to the opportunities and threats that exist due to the outside world. If the individual doing the analysis is a female engineer focusing her analysis on career and family, some factors from the external area could be:

1. Need for families to have two incomes to enjoy a high standard of living

2. Her desire to have children

3. Possibility to work at home in professional jobs through the virtual office

4. Anti-discrimination laws

5. Social acceptance of women in engineering

6. Availabilities or nannies from other countries

These are trends in the outside world, beyond the subject's control, which affect what she can and cannot do relative to her decision. The factors in the economic, technical, political/legal and socio-cultural areas, which are part of the environment, are legion. The skill of environmental analysis is the selection of those that are obstacles or facilitators to the strategies that might be employed.

\section{Internal Environment}

The factors here would relate to the pertinent strengths and weaknesses of the individual relative to the subject question. If the individual doing the analysis is, again, a female engineer focusing her analysis on career and family, some factors from the internal environment could be:

1. Integrates well with peer groups

2. Able to handle tight time schedules

3. Enjoys working in science related areas 
4. Good at working through delegation

5. Will be happier working than staying home

6. Can work in isolation productively

The factors detailed in the Environmental section form the fabric of what can and cannot be done efficiently by the individual. It is a SWOT analysis whether one is talking about an individual or a corporation.

\section{Strategy Formulation}

\section{Mission/Objectives}

The Mission/Objectives is the area that gives the student the most difficulty. Their first pass is something like 'I want to be happy'. At that point the questions of what will make you happy or make you feel it was a successful life for you, tends to help them. Breaking their mission down into subsections of health, career etc. is also helpful. If all else fails, to ask them to write their desired obituary. This often brings them into contact with what is really important to them.

For the person addressing health as an area, the mission statement may be as simple as: To be in control of their health situation.

\section{Strategy/Policy}

Strategy is the section that tells us how we are going to accomplish the mission. For the person analyzing their health situation, a strategy may be:

1. To become proactive in pursuit of health monitoring

2. To pursue alternate health programs

\section{Strategy Implementation}

Strategy implementation is, the operational end of the strategy. What are we actually going to do? Again, for the person focusing on health implementations may be:

1. Join a health Club

2. Workout 3 hours per week

3. Arrange a physical once per year. Etc

\section{Evaluation \& Control}

Evaluation \& Control involves setting up standards of performance and detailing how they will be measured. Again for our health candidate this could include comments such as:

1. Establish a log and journal covering all doctor visits and journal them. Journal will be reviewed each year on January 1 to determine any changes required.

2. A log will be kept of all exercise periods, which will be summed each month and reviewed relative to desire three hours per week standard.

The evaluation and control section is the feedback process for the strategic planning model. Reviews at the appointed junctures will indicate if goals are being met and indicate what should be done to modify methods and goals.

The examples above are minimal and simplistic by comparison to output of the model, but are illustrative. 


\section{BENEFITS OF LIFE PLANNING}

The benefits of this type of analysis are many. A few are summarized below:

1. This type of analysis can be repeated on a periodic basis, such as yearly. By so doing the changes in environments and directions can be incorporated into the analysis and prescription.

2. It establishes relationships between events and goals that are difficult to asses and understand without such an analysis.

3. It also allows consideration of many factors simultaneously. Their interactions can be analyzed.

4. $\quad$ Changes and their impact can be tracked.

5. The separation of types of considerations is important.

6. Actions can be broken down.

7. The results are modified which can lead to changes in methods to accomplish ends or changes in ends themselves.

\section{WARNING}

A life plan can be a traumatic experience for some student, since it can cause them to face decisions, which are a true dilemma to them. Students are advised of this and offered an alternate assignment, if they feel it is an assignment that they cannot psychologically handle. Students must be advised that, if they are in therapy they are not to attempt the project without discussing it with their therapist.

\section{CONCLUSION}

This is a critical area on which to start student before they leave their college environment. The model works well in accomplishing its objective. It fits well in a strategy course, since it tests the understanding of the model in a different arena and yields a lifetime benefit, if followed by the student.

\section{REFERENCES}

1. Business Wire inc., Forefield and Mitch Anthony's Institute for Financial Life Planning Partner to Provide Financial Advisors with Comprehensive Life Planning Platform, Business Wire, Marlboro, Mass. And Rochester, Min., Sept 23, 2004

2. Hollis, Joseph W and Lucile U. Hollis, Career and Life Planning, Accelerated Development Inc., Muncie, IN, 1997

3. Miller, Rick, With George D. Kinder of Kinder \& Co. Crain Communications Inc., September 13, 2004, pg. 66

4. $\quad$ Perry, Ann, Money and You, Copley News Service, Washington DC, June 23, 2003.

5. Southall, Brooke, Life-planning movement sustains split, Crain Communications Inc., March 1, 2004.

6. Wasik, John F., 9-11 awakens need for solid life planning, Ventura Country Star, September 14, 2003.

7. Wheelen, Thomas L. and Hunger, J. David, Strategic Management and Business Policy $9^{\text {th }}$ ED., Prentice Hall. Upper Saddle River, NJ, 2004 